\title{
Article \\ The EU-SENSE System for Chemical Hazards Detection, Identification, and Monitoring
}

\author{
Małgorzata Gawlik-Kobylińska ${ }^{1,2, *} \mathbb{0}$, Grzegorz Gudzbeler ${ }^{1}$, Łukasz Szklarski ${ }^{3}$, Norbert Kopp ${ }^{4}$, \\ Helge Koch-Eschweiler ${ }^{4}$ and Mariusz Urban ${ }^{1}[$ \\ 1 Faculty of Political Science and International Studies, University of Warsaw, 00-927 Warsaw, Poland \\ g.gudzbeler@uw.edu (G.G.); mp.urban@uw.edu (M.U.) \\ 2 Faculty of Command and Management, War Studies University, 00-910 Warsaw, Poland \\ 3 ITTI, 61-612 Poznań, Poland; lukasz.szklarski@itti.com.pl \\ 4 Technisch-Mathematische Studiengesellschaft mbH (tms), 53229 Bonn, Germany; \\ n.kopp@tms-bonn.de (N.K.); h.koch@tms-bonn.de (H.K.-E.) \\ * Correspondence: m.gawlik-kobylinska@uw.edu.pl
}

\section{check for}

updates

Citation: Gawlik-Kobylińska, M.; Gudzbeler, G.; Szklarski, Ł.; Kopp, N.; Koch-Eschweiler, H.; Urban, M. The EU-SENSE System for Chemical Hazards Detection, Identification, and Monitoring. Appl. Sci. 2021, 11, 10308. https://doi.org/10.3390/ app112110308

Academic Editors:

Malgorzata Pankowska and Emilio Insfran

Received: 8 September 2021

Accepted: 29 October 2021

Published: 3 November 2021

Publisher's Note: MDPI stays neutral with regard to jurisdictional claims in published maps and institutional affiliations.

Copyright: (c) 2021 by the authors. Licensee MDPI, Basel, Switzerland. This article is an open access article distributed under the terms and conditions of the Creative Commons Attribution (CC BY) license (https:// creativecommons.org/licenses/by/ $4.0 /$ )

\begin{abstract}
Chemical reconnaissance, defined as hazards detection, identification, and monitoring, requires tools and solutions which provide reliable and precise data. In this field, the advances of artificial intelligence can be applied. This article aims to propose a novel approach for developing a chemical reconnaissance system that relies on machine learning, modelling algorithms, as well as the contaminant dispersion model to combine signals from different sensors and reduce false alarm rates. A case study of the European Union Horizon 2020 project-EU-SENSE is used and the main features of the system are analysed: heterogeneous sensor nodes components, chemical agents to be detected, and system architecture design. Through the proposed approach, chemical reconnaissance capabilities are improved, resulting in more effective crisis management. The idea for the system design can be used and developed in other areas, namely, in biological or radiological threat reconnaissance.
\end{abstract}

Keywords: chemical detection; chemical identification; chemical monitoring; chemical reconnaissance; machine learning; modelling algorithms

\section{Introduction}

Chemical hazards may cause severe damage to societies and the environment. Their effect on human beings, organic life, food and water supplies, and infrastructure [1-3] may be a result of a human or organizational activity [4], or natural disaster [5]. While defining chemical hazards, which can occur in the form of a solid, liquid or gas, the focus is on their toxicity-the amount or degree of a substance needed to be poisonous [6] (p. 482). Toxicity relates to durability, the time in which the chemical material retains its toxic qualities after use. Chemical hazards may be non-persistent, being volatile and evaporating quickly, from a few minutes to an hour. There are also semi-persistent chemicals, which remain in space from a few hours to one day, and persistent chemicals that often have dense and oily structures and can last from a few days to several weeks. Their persistence depends primarily on meteorological conditions, volume, and dissemination means. The abovementioned qualities of chemical hazards play a significant role, while environmental reconnaissance (detection, identification, and monitoring-DIM) is performed in the case of any unexpected or predicted release. It should be emphasised that the existence of the substance does not determine its effectiveness, but when misused, it can be turned into a weapon of mass destruction (WMD), which encompasses chemical warfare agents (CWAs) and a broad range of toxic industrial chemicals (TICs) [7] (p. 39). CWAs are "extremely toxic synthetic chemicals that can be dispersed as a gas, liquid or aerosol or as agents adsorbed to particles to become a powder" [8], while TICs are created and 
used in medical or industrial settings and when released to the environment may harm human health [9]. Their misuse can be related to either their properties or the potential to interact with the environment or other substances. The mitigation and reduction of threats resulting from the CWAs and TICs require quick and prompt reconnaissance activities. Human senses have limited capacity to detect chemical agents, even those which pose a risk to human health and life. Therefore, it is necessary to support the perception of human senses by instruments or sets capable of chemical threat reconnaissance. There are various devices for chemical reconnaissance [10-12]; they can rely on different methods of chemical detection and identification (for instance, ion mobility spectrometry-IMS, flame photometry, infrared spectroscopy - IR spectroscopy, surface acoustic wave, colorimetry, Raman spectroscopy) [13]. Usually, they are used as separate tools integrated within a checkpoint. However, with technological advancements, there are greater possibilities for taking more complex countermeasures against chemical attacks [14-16]. Artificial intelligence, space capabilities, big data, and high-performance computing are technologies that facilitate the development of solutions for keeping society and the environment safer and more secure [17]. Their use may allow for different functionalities integration and an increase in reconnaissance capabilities by providing fast, clear, and reliable data.

In this article, an approach to chemical reconnaissance system development is proposed that relies on cutting-edge technologies, i.e., a novel network of integrated sensors that exploits advanced machine-learning, modelling algorithms, and contaminant dispersion models. The integration and synchronisation of different sensors increases the reconnaissance capabilities and reliability (mainly through a false alarm rate reduction) of the whole system.

As a research approach, a systemic analysis of the case study concerning the system development is used. In particular, heterogeneous sensor nodes components, chemical agents to be detected, and EU-SENSE system architecture with its three layers are analysed. The system and its accompanying tools were created within the European Sensor System for CBRN Applications (EU-SENSE) project involving nine European partners. This case study contributes to the application of artificial intelligence in chemical reconnaissance. Moreover, it proposes a novel approach for the use of AI for the needs of the environment, particularly in chemical, biological, radiological, and nuclear (CBRN) security and safety.

\section{Chemical Sensors Overview}

Since chemical hazards pose threats to human health, safety, and the environment, instruments for reducing risks related to chemical substance release are developed. The main objective of chemical detectors is to alarm the user to the emergence of a threat as early as possible. Their most essential properties may vary from their capability to detect agents (i.e., selectivity, sensitivity, response time, and false alarm rate) to performance (warm-up time, calibration, mobility, power supply, as well as training and maintenance costs) [18].

Currently available sensors are based on technologies stemming from analytical chemistry. The most common include:

1. Ion mobility spectrometry (IMS): A sensor draws an air sample into the reaction area, where it is ionized. A detector plate registers the time at which the ions cross the tube. The plot of the ion current that is generated over a given period indicates the concentration of the agent [19]. IMS was infrequent until the first IM-MS (ion mobility-mass spectrometry) instruments were launched onto the market [20];

2. Flame photometry: This kind of sensor burns an air sample, which emits light of a specific wavelength, which is extracted by an optical filter. Most known elements produce a wavelength that is sufficiently characteristic to allow for an accurate identification [21];

3. Infrared spectroscopy (IR spectroscopy): A gas is exposed to radiation in the range of 2.5-25 micrometres, which passes through it and is then absorbed in wavelengths characteristic for certain elements. IR spectroscopy is used in sensors detecting blisters 
and nerve agent vapours. IR-based sensors used in field conditions evaluate whether the sample contains a given chemical, rather than providing full identification. A rapidly emerging technique is atomic force microscopy-based infrared spectroscopy (AFM-IR) [22];

4. Surface acoustic wave: A detector detects slight changes in the acoustic waves that interact with the matter attached to the surface of a piezoelectric material [23,24]. A characteristic pattern of these changes can identify particular blister and nerve agent classes [19];

5. Colorimetric-chemical reactions between various solutions and substrates, and agents, result in colour change $[25,26]$. This is one of the oldest and most cost-efficient detection techniques used to detect and identify nerve, blister, and blood agents [27];

6. Raman spectroscopy: A light-scattering technique that uses radiation which is passed through a transparent medium and scattered in various directions depending on the present substances. It is very effective and used for the quick detection of narcotics, explosives, and chemicals $[27,28]$.

Other detection technologies rely on photoacoustic IR spectroscopy, gas chromatography (GC), Fourier transform infrared (FTIR) spectrometry and thermoelectric conductivity. From this overview, it can be noticed that there is a vast choice of sensor technologies. However, none of them can meet every need and performance requirement voiced by the users. It is an additional challenge to researchers and developers to create a solution that would offer the possibility of using multiple sensors based on various technologies for threat detection and identification at the same time, under one system or network of sensors.

\section{Methods}

A case study is used to introduce a new approach for chemical reconnaissance system development. The systemic analysis will concern the European Sensor System for CBRN Applications-EU-SENSE project (2018-2021) [29]. An abductive mode of reasoning was used. This kind of reasoning begins with an analysis of the case and then seeks the simplest and most likely outcomes from the analyses. It is vital to stress that this case study is of an explanatory nature. It means that the pattern of research and development activities can be applied to create other, similar solutions.

\subsection{EU-SENSE Case Study}

The analysis of the case study will involve presenting the background situation (rationale and objectives of the project), heterogenous sensor node components, chemical agents to be detected with the EU-SENSE system, and finally, the EU-SENSE system architecture (situational awareness layer, computational layer, and network layer).

\subsubsection{EU-SENSE Project Rationale and Objectives}

The International Forum to Advance First Responder Innovation (IFAFRI), as well as H2020 ENCIRCLE project, both highlighted the importance of real-time detection, monitoring, and analysis of CBRN threats and hazards. Tackling this priority requires bridging existing technological and capability gaps in the scope of first responders' work, who must safely and promptly identify hazardous agents and contaminants [30]. To improve the detection, identification, and monitoring of chemical threats, the European Sensor System for CBRN Applications-EU-SENSE project was developed [31,32]. EUSENSE focuses on developing a modern network of sensors for CBRN applications, both stationary and person-worn. The proposed network integrates heterogeneous sensor nodes, innovative data processing algorithms, as well as computational tools. A unified data model maintains the interoperability of the network components working with heterogeneous data. Specific EU-SENSE objectives are:

- Contributing to better situational awareness of the CBRN practitioners through the development of a novel network of chemical sensors; 
- Improving the reconnaissance capabilities of the novel network of chemical sensors using machine learning algorithms (to reduce the false alarm rate) and the application of contaminant dispersion models, showcasing the usability of the EU-SENSE network to CBRN practitioners to validate the system, and maximizing its exploitation potential. The objective also involves the preparation of training sessions with CBRN practitioners [31].

\subsubsection{Heterogeneous Sensor Node Components}

The EU-SENSE system focuses on a sensor node, which combines different detection technologies (therefore, it is called heterogeneous). The reason for the diversification of detection technologies is the increase in the spectrum of detectable substances and the availability of rich datasets for the application of data fusion algorithms. By applying data fusion and machine learning, the system can reduce the number of false alarms, and classify and identify the detected substance. In the design and development of a heterogeneous sensor node, the following detectors were integrated:

- Airsense IMS detector with ammonia chemistry with integrated photon ionisation detector (PID);

- $\quad$ Airsense IMS detector with water chemistry with integrated electrochemical cell (EC);

- Proengin AP4C flame photometric detector (FPD);

- TNO SRD metal oxide detector prototype.

The EU-SENSE system, through machine-learning, is also able to limit the impact of the false alarm rate on the sensor readouts, and thus, produce fewer false alarms. The system learns the environmental conditions in the area where the network is deployed and detects the anomalies. Based on the anomaly detection results, the system performs data fusion classification and identification to determine whether the detected anomaly is harmful or not.

If the alarm is triggered, the EU-SENSE system enables end-users to estimate the source of the hazard because of the source location estimation tool. Moreover, the system provides crucial functions such as modelling the dispersion of a toxic chemical substance. These functionalities largely increase the situational awareness of the first response units, aiding them to apply countermeasures and evacuation.

\subsubsection{Chemical Agents to Be Detected}

As mentioned above, two groups of hazardous chemical agents can be distinguished: chemical warfare agents (CWA) and toxic industrial chemicals (TICs). There are also various classes of chemical agents. Bland (2014) indicates nerve agents, blistering agents (vesicants), cyanides (blood agents), pulmonary agents (choking or lung-damaging agents), incapacitants (both mental and physical), toxic industrial chemicals (TICs), riot control agents (RCAs), and pharmaceuticals [33]. There are three types of agents: non-persistent (gaseous); persistent; and thickened, non-persistent. Non-persistent agents are disseminated mainly as vapour or may leave unevaporated liquid in shell or bomb craters. Persistent agents are disseminated as liquid and constitute a vapour hazard as well as a contact hazard. Thickened, non-persistent agents can be treated as persistent, ground contaminating agents [34].

With the EU-SENSE sensor node, the following chemical warfare agents (CWA) will be detected: tabun (GA) (nerve agent, persistent), sarin (GB) (nerve agent, non-persistent), soman (GD) (nerve agent, non-persistent/persistent), cyclosarin (GF) (nerve agent, persistent), VX (methylphosphonothioic acid) (nerve agent, persistent), sulphur mustard (HD, Yperite) (blister agent, persistent), and lewisite 1 (L) (blister agent, persistent). Regarding toxic industrial chemicals (TICs), these are: ammonia $\left(\mathrm{NH}_{3}\right)$, chlorine $\left(\mathrm{Cl}_{2}\right)$, sulfur dioxide $\left(\mathrm{SO}_{2}\right)$, hydrogen cyanide $(\mathrm{HCN})$ and hydrogen sulfide $\left(\mathrm{H}_{2} \mathrm{~S}\right)$, all non-persistent gases [35]. 


\subsubsection{EU-SENSE System Architecture}

EU-SENSE system architecture consists of three layers: the situational awareness layer, the computational layer, and the network layer (Figure 1) [36].

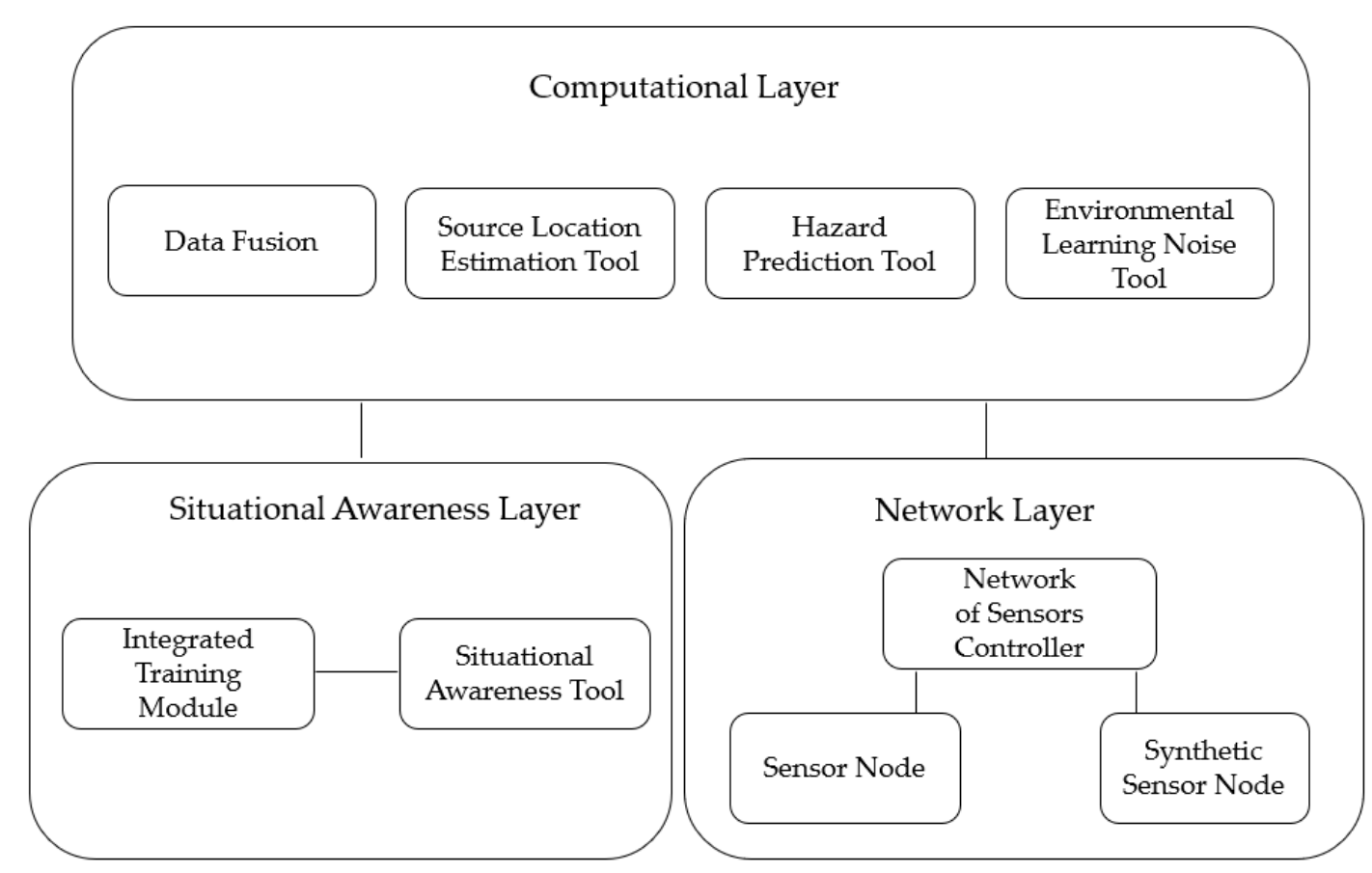

Figure 1. EU-SENSE system architecture [36].

Situational Awareness Layer

The first layer consists of the integrated training module and the situational awareness tool. It integrates data from the sensors' network and data fusion output. The data are displayed on the map, allowing CBRN trainees to take further steps while managing a crisis.

\section{Computational Layer}

This layer includes four data processing tools: data fusion, a source location estimation tool, a hazard prediction tool, and an environmental noise (false alarm rate) learning tool. The data fusion algorithm combines data from the sensors, advanced machine learning and modelling algorithms. The hazard prediction tool relies on an FOI (Swedish Defence Research Agency, Totalförsvarets forskningsinstitut-FOI) dispersion engine that allows air dispersion calculations to predict concentration levels following a chemical release [37]. The source location estimation tool runs an inverse version of the FOI dispersion engine simultaneously with an optimization algorithm to calculate the source's strength and position [36]. The last component, the environmental learning noise tool, implements algorithms that process incoming raw sensor data and checks if the situation becomes stable (through normality detection). It works as a standalone system.

\section{Network Layer}

The network layer includes the network of sensors controller composed of sensor node and synthetic sensor nodes. The internal communication between them relies on WiFi devices and their protocols. The network of sensors controller consists of sensor nodes that integrate individual sensors. The arrangement is called a tree topology network. The network of sensors controller includes three components: process control, runtime configuration, and a local database for sensor storage. It acts as a communication and 
direct management tool. Specifically, it collects and decodes raw streams from connected sensor nodes; transits data from the sensor nodes to the local database, configures and reconfigures sensor nodes; and checks network component status. The network controller provides both live and historical data. An SD card stores all information related to the node configuration (e.g., addresses of Bluetooth devices or node identification parameters).

A heterogeneous sensor node contains a variety of chemical sensors based on different technologies that function within the same node. With this solution, a large amount of data are gathered. Data fusion algorithms are simultaneously responsible for detecting and identifying chemical agents, and reducing the false alarm rate. The sensor node unit comprises sensors for chemical detection, a node controller based on an STM32F4 microcontroller, pre-processing algorithms and configuration components [36]. The sensors can be person-worn or stationary.

It must be stressed that for the EU-SENSE system, ensuring sensor node interoperability is the challenge. Data in different formats, schemas, models, and discrepancies in third party devices (e.g., Proengin FDP detector and TN MO detector) require the creation of a unified data model. This model involves two elements, a network configuration standard (implemented as a set of XML files) and a set of files describing communication between the system components (mainly protobuf format files) [36].

\subsubsection{Demonstration of the EU-SENSE System}

The first practical demonstration of the system was held in October 2021 at the Training and Rescue Innovation Base in Nowy Dwór Mazowiecki (a town in Poland), a training facility of the Main School of Fire Service in Warsaw [38]. The consortium showcased both the system's operation in a mass incident (phase of crisis preparation) and a toxic industrial event (phase of crisis response, ammonia leakage). During the demonstration, it was proved that the EU-SENSE system could be used in various crises, and a plan for its further development was outlined. The demonstration participants $(n=21)$ represented the military, research institute end-users, counter-terrorism representatives, and private companies focusing on CBRN topics. The participants' observations, opinions and comments were gathered. Analysis of the feedback revealed that all respondents positively evaluated the EU-SENSE system, indicating its versatility based on a novel approach to hazards detection.

\subsubsection{Applicational Potential}

The EU-SENSE system is designed to enhance chemical hazards detection capabilities. It can be used during chemical, biological, radiological, and nuclear (CBRN) incidents. Such incidents result from a release of various agents, and require appropriate hazard management, including the employment of special units to combat the situation, warning and reporting activities [39-42]. CBRN defence is the umbrella term for all these situations [43].

According to ATP-45(D), chemical agents are likely to be used to produce casualties (non-persistent effect) or to contaminate ground and /or equipment (persistent effect) [34].

Moreover, the type of chemical agent is related to target conditions. For example, forward troops may be subjected to a quick dispersion vapour such as hydrogen cyanide in a ground attack. Mobile units are vulnerable to an attack with a fast-acting nerve agent, such as sarin or soman. In airfields and depots, persistent agents, which contaminate surfaces and produce a downwind hazard, can be used. Naval forces at sea are likely to be attacked by thickened or persistent agents such as TGD or HL (mustard-lewisite mixture). Ships near shore are at risk from vapour hazards associated with attacks on land targets [44]. The EU-SENSE system (Figure 1), with its unique sensor node (Figure 2), aims to serve as a versatile tool detecting various chemical agents in different conditions. 


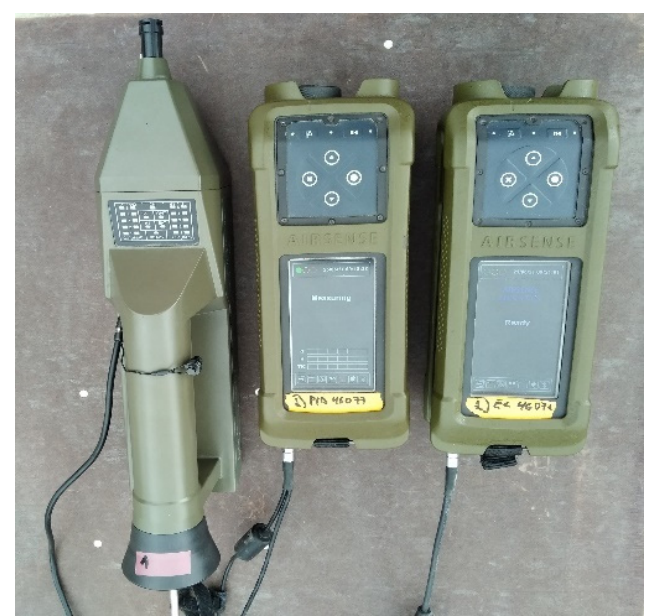

(a)

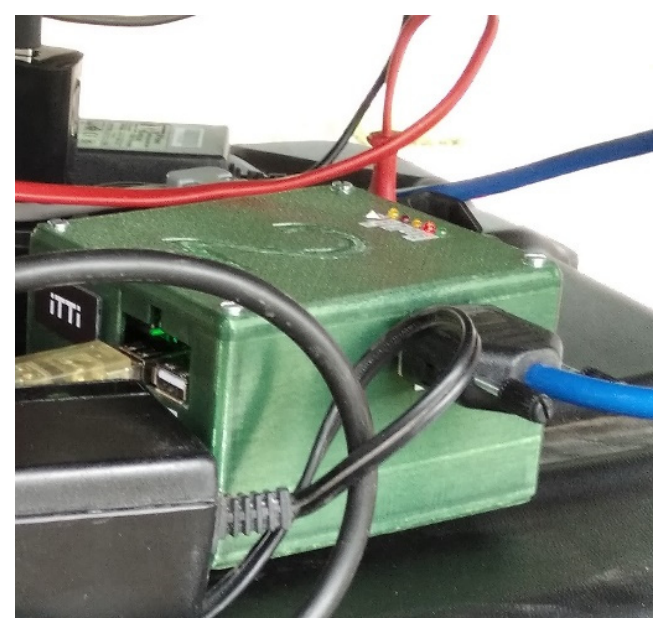

(b)

Figure 2. EU-SENSE system prototype. (a) EU-SENSE detection tool; (b) Sensor node.

Recipients of the system are CBRN practitioners, being, among others, first responders (medical personnel, fire brigade, military personnel) who constitute a specialized group to arrive on the scene [45] and commanders who manage the crisis.

\subsubsection{Sensor Data Fusion and Machine Learning}

The network generates a continuous stream of data consisting of the different sensor responses (IMS spectra, MO sensor channels, and response of the FPD, PID and EC). This amount of data from the different sensors and nodes, arriving at a sampling rate of $1 \mathrm{~Hz}$, makes some sensor data fusion mandatory.

The main tasks in EU-SENSE where data fusion and ML play a role are, one, detection of an incident, and, two, estimation of the concentration of the released agent. Detection (in the sense of "detect-to-warn") is the decision of whether a (real) incident has occurred or not. Incident means the presence of a harmful substance concentration. In this case, the detection should follow as early and reliably as possible.

In mathematical terms, detection is about classification, and concentration is about regression. Classification and regression are two of the most common types of machine learning tasks, and there exists a rich set of methods to treat classification and regression.

In the EU-SENSE project, the detection is performed in two steps. The first step is anomaly detection, followed by an identification step.

Anomaly detection shows a change, being an unusual, possibly harmful situation, in the incoming time series of sensor responses. This recognition of anomaly detection is based on raw sensor data collected from individual sensors. These sensors are combined into "sensor nodes" and, at a higher level, a network of sensor nodes. Therefore, anomaly detection can occur on sensor level, node level and/or the network level. The method used is a statistical, distance-based approach that compares incoming response values against (multi-variate) probability distributions learned continuously from previously seen data (online learning) in different schemes. The results of anomaly detection are a new (one-dimensional) time series (on sensor level, node level, etc.) of anomaly scores. On one hand, these anomaly scores are very sensitive; on the other hand, they ignore normal environmental noise by learning the statistical clutter characteristics. However, the process is still so sensitive that false positives are unavoidable as:

- It detects small concentrations;

- It detects signals of harmless substances;

- It detects artefacts. 
In this context, it is interesting to reflect for a moment what a false alarm actually is. Is it a false alarm when there is a (low) concentration of a harmless substance in the air containing, e.g., phosphorus (fertiliser)? And does the AP4C (P channel) respond to that? The AP4C does exactly what it is supposed to do, and from this perspective, it is not a false alarm. However, it is a false alarm for emergency personnel since the substance is harmless in a low concentration. Therefore, the next step is to verify whether an identified anomaly is a real incident. It is an identification phase.

Identification is possible by learning the response characteristics of several different sensors and their responses to different substances. In the EU-SENSE project, IMS technology facilitates the identification process. The methods used for identification are a combination of machine learning methods and the utilisation of the specific sensor capabilities. As the primary tool, Bayesian inference in the form of Bayesian networks is used. Bayesian inference is about knowledge, and it can be defined as: acquiring new knowledge from given knowledge contained in the Bayesian network. The relation between the nodes of a Bayesian network contain knowledge in the form of conditional probabilities. These probability distributions must be learned from experimental data, and the knowledge is in the following form: given a certain substance $x$ and a certain concentration $y$, then the probability distribution of the (multivariate) sensor response is z. Bayesian networks not only allow solving of the classification and regression (concentration estimation) tasks, they are also common in sensor data fusion [46-48].

In summary, the detection relies on tracing anomalies, making it very sensitive, and then the identification process, on the basis of which the whole detection process is reliable.

\section{Results and Discussion}

The most likely outcomes from the analysis of the case study are:

1. The main result of the project is the EU-SENSE system, based on machine learning algorithms that work with data coming from different nodes. The system's advantage is to reduce noise from the environment (false alarm rate). When an anomaly is detected in the environmental noise, inverse dispersion modelling is used for source characterization. As a result, the source position and the source strength are reliably estimated;

2. The EU-SENSE system is a versatile, state-of-the-art solution that will enhance the work of CBRN practitioners. Data on hazardous substances are gathered systemically and more effectively when compared with a situation where CBRN personnel use different devices to detect a chemical hazard. The incoming data are formatted, and, in case of large contamination, are sent to a CBRN warning and reporting centre;

3. Introducing a new system often involves training. In the case of the EU-SENSE system, a training mode was proposed. It will involve a case study approach and simulation;

4. A framework for research and development activities can be applied in other work on developing sensors for testing environments. A problem-solving theory can stipulate other eventual commercial products [49].

Regarding the above, the EU-SENSE system offers significant improvements in the situational awareness of first responders. Based on the application of computational tools, practitioners can better assess the situation and apply countermeasures with an improved coordination.

It should be stressed that the EU-SENSE project is closely related to environmental security and safety as it focuses on chemical reconnaissance. Chemical agents or toxic industrial chemicals are often used (or generated as waste) in the technological process of industrial plants. Potential incidents and breakdowns might lead to a contamination threat of the local environment on a large scale [50,51]. In such scenarios, the EU-SENSE system will help first responders monitor the threat and its dispersion over the area of interest. During the operation, the network will enable real-time data analysis from the deployment site through the situational awareness tool, which serves as the main access point to the system. 
Moreover, the system can support critical infrastructure resilience. Critical infrastructure is vulnerable to different natural influences, including natural disasters [52] and they may cause the release of chemicals $[53,54]$. In such a situation, the system, which relies on data from many sensors, can be a reliable tool for immediate hazards analysis. Critical infrastructure can also be threatened by terrorist activities $[55,56]$. In order to combat any human-made threat, sensors can be used in drones or other robotic vehicles. In these contexts, the EU-SENSE system can aid CBRN practitioners in saving the natural environment by reducing potential side effects for human health. The use of the system will also help public services to organise more efficient and better-prepared actions.

In addition, any novel system requires training. The training module, which is a part of the situational awareness layer, serves as an example of practices that should be followed. The design of the didactic activities should be intuitive and based on usability attributes [57]. In further research and development works, the instructions could be generated by artificial intelligence [58].

It is vital to stress that NATO countries use uniform procedures in the warning and reporting system (ATP-45). This paves the way for wide dissemination and use of the project results. The introduction of machine learning as part of the analysis can improve the assessment of contamination situations and support CBRN specialists in their work, especially in a large CBRN event (cross-border) and the need to process large amounts of data. Current CBRN information management programs do not have this functionality [59].

Future study could include integrating sensors into autonomous and swarm-based robot systems. Swarm robots or unmanned vehicles can monitor the environment, search for the hazardous environment [60,61], or grade the risk value [62]. In this case, new artificial intelligence-based research activities such as efficient communication protocols, efficient use of sensor energy, optimal environment coverage in mobile sensor nodes, autonomous movement, CBRN risk assessment, intelligent decision making and selforganized response strategies without human commanders in swarm robots can be carried out.

Last, but not least, the system's design can be used in further research and development activities regarding the detection, identification, and monitoring of biological or radioactive contamination. In the case of biosensors, the available techniques for the complete detection of pollutants are insufficient [63] and the diagnosis of biological contamination is still a considerable challenge. Radiological standard detectors are often burdened with weaknesses, such as a low signal level at normal radiation protection dose rates or susceptibility to temperature and humidity corrections [64]. The use of machine learning algorithms may at least improve detection capabilities.

\section{Conclusions}

1. This case study aimed to propose a novel approach to chemical reconnaissance system development. It proposed using machine learning, modelling algorithms and a contaminant dispersion model to combine signals from different sensors, and to reduce the false alarm rate. From proof of concept to a prototype, this study analysed the development of the EU-SENSE, specifically heterogeneous sensor nodes components, chemical agents to be detected, and EU-SENSE system architecture with situational awareness, computational, and network layers. The authors believe that the development of such devices will trigger new approaches to chemical reconnaissance. Effectiveness in a less predictable environment must be more rapid, reliable, and flexible. Therefore, more advanced solutions based on artificial intelligence should be developed to help CBRN first responders act more effectively;

2. The confidence of future system users will be built through special training on the system functionalities and use in the field. The training modes will rely on the active didactic methods: case study analysis and a simulation;

3. The proposed design of the system developed with the research and development activities can be used in other areas, namely in biological or radiological threat 
detection. Future directions of research and development works can be proposed in this area.

Author Contributions: Conceptualization, M.G.-K., N.K. and H.K.-E.; methodology, M.G.-K., N.K. and H.K.-E.; resources, G.G., Ł.S., N.K., H.K.-E. and M.U.; writing-original draft preparation, M.G.K., G.G., Ł.S. and M.U.; writing—review and editing, M.G.-K., G.G., Ł.S., N.K., H.K.-E. and M.U.; visualization, M.G.-K. and Ł.S.; supervision, G.G., N.K. and H.K.-E.; project administration, G.G. and Ł.S.; funding acquisition, G.G. and Ł.S. All authors have read and agreed to the published version of the manuscript.

Funding: This research was funded by the Horizon 2020: European Union Programme for Research and Innovation, grant agreement ID 787031.

Institutional Review Board Statement: Not applicable.

Informed Consent Statement: Not applicable.

Data Availability Statement: Not applicable.

Conflicts of Interest: The authors declare no conflict of interest. The funders had no role in the design of the study; in the collection, analyses, or interpretation of data; in the writing of the manuscript, or in the decision to publish the results.

\section{References}

1. European Commission. Commission staff Working Document. In Overview of Natural and Man-Made Disaster Risks the European Union May Face; European Commission: Brussels, Belgium, 2021.

2. Sun, Y.; Qian, X.; Liu, Y.; Wang, J.; Lv, Q.; Yuan, M. Identification of Typical Solid Hazardous Chemicals Based on Hyperspectral Imaging. Remote. Sens. 2021, 13, 2608. [CrossRef]

3. Henretig, F.M.; Kirk, M.A.; McKay, C.A., Jr. Hazardous Chemical Emergencies and Poisonings. N. Engl. J. Med. 2019, 380, 1638-1655. [CrossRef] [PubMed]

4. Li, X.; Liu, T.; Liu, Y. Cause Analysis of Unsafe Behaviors in Hazardous Chemical Accidents: Combined with HFACs and Bayesian Network. Int. J. Environ. Res. Public Health 2019, 17, 11. [CrossRef] [PubMed]

5. Đokic, J.; Arsic, N.; Milentijevic, G. Natural Disasters in Industrial Areas. In Natural Risk Management and Engineering: NatRisk Project; Gocić, M., Aronica, G.T., Stavroulakis, G.E., Trajković, S., Eds.; Springer: Berlin/Heidelberg, Germany, 2020 ; pp. 89-114.

6. Brooker, C. Churchill Livingstone Medical Dictionary E-Book; Elsevier Health Sciences: Norfolk, UK, 2008.

7. Steinhausler, F.; Steinhäusler, F.; Edwards, F. (Eds.) NATO and Terrorism Catastrophic Terrorism and First Responders: Threats and Mitigation; Springer Science \& Business Media: Dordrecht, The Netherlands, 2005; Volume 2.

8. Ganesan, K.; Raza, S.K.; Vijayaraghavan, R. Chemical warfare agents. J. Pharm. Bioallied Sci. 2010, 2, 166-178. [CrossRef] [PubMed]

9. NYC Health, Toxic Industrial Chemicals. City of New York: N.d. Available online: https://www1.nyc.gov/site/doh/health/e mergency-preparedness/emergencies-chemical-toxic-industrial-chemicals.page (accessed on 1 October 2021).

10. Vaseashta, A.; Khudaverdyan, S. (Eds.) NATO Science for Peace and Security Studies Series-B: Physics and Biophysics. In Advanced Sensors for Safety and Security; Springer: Dordrecht, The Netherlands, 2013.

11. Hua, M.Z.; Li, S.; Wang, S.; Lu, X. Detecting chemical hazards in foods using microfluidic paper-based analytical devices ( $\mu$ pads): The real-world application. Micromachines 2018, 9, 32. [CrossRef]

12. Tørnes, J.A. A novel headspace sampler for field detection of chemical warfare agents and simulants connected to a commercial ion mobility detector. Int. J. Ion Mobil. Spectrom. 2016, 19, 105-112. [CrossRef]

13. Mesilaakso, M.E. Chemical Weapons Convention Chemicals Analysis: Sample Collection, Preparation and Analytical Methods; John Wiley \& Sons Ltd.: Chichester, UK, 2005.

14. Martellini, M.; Trapp, R. (Eds.) 21st Century Prometheus: Managing CBRN Safety and Security Affected by Cutting-Edge Technologies; Springer Nature: Cham, Switzerland, 2020.

15. Koblentz, G.D. Emerging Technologies and the Future of CBRN Terrorism. Wash. Q. 2020, 43, 177-196. [CrossRef]

16. Reding, D.F.; Eaton, J. Science \& Technology Trends 2020-2040. Exploring the SET Edge; NATO Science \& Technology Organization: Brussels, Belgium, 2020.

17. European Commission. Communication from the Commission on the EU Security Union Strategy; European Commission: Brussels, Belgium, 2020.

18. Sun, Y.; Ong, K.Y. Detection Technologies for Chemical Warfare Agents and Toxic Vapors; CRC Press: Boca Raton, FL, USA, 2004.

19. Spencer, R.C. Chemical and Biological Terrorism: Research and Development to Improve Civilian Medical Response; The National Academies Press: Washington, DC, USA, 1999. [CrossRef]

20. Hernández-Mesa, M.; Escourrou, A.; Monteau, F.; Le Bizec, B.; Dervilly-Pinel, G. Current applications and perspectives of ion mobility spectrometry to answer chemical food safety issues. TrAC Trends Anal. Chem. 2017, 94, 39-53. [CrossRef] 
21. Stela, M.; Ceremuga, M.; Szyposzyńska, M.; Spławska, A.; Mirosz, D.; Truszkowska, K. Detection of chemical contaminants. In CBRN. Security Manager Handbook; Bijak, M., Ed.; University of Łódź: Łódź, Poland, 2018; pp. 409-459.

22. Dazzi, A.; Prater, C.B. AFM-IR: Technology and Applications in Nanoscale Infrared Spectroscopy and Chemical Imaging. Chem. Rev. 2017, 117, 5146-5173. [CrossRef]

23. Mujahid, A.; Dickert, F.L. Surface Acoustic Wave (SAW) for Chemical Sensing Applications of Recognition Layers. Sensors 2017, 17, 2716. [CrossRef]

24. Go, D.B.; Atashbar, M.Z.; Ramshani, Z.; Chang, H.C. Surface acoustic wave devices for chemical sensing and microfluidics: A review and perspective. Anal. Methods 2017, 9, 4112-4134. [CrossRef]

25. Kangas, M.J.; Burks, R.M.; Atwater, J.; Lukowicz, R.M.; Williams, P.; Holmes, A.E. Colorimetric Sensor Arrays for the Detection and Identification of Chemical Weapons and Explosives. Crit. Rev. Anal. Chem. 2017, 47, 138-153. [CrossRef] [PubMed]

26. Fernandes, G.M.; Silva, W.R.; Barreto, D.N.; Lamarca, R.S.; Gomes, P.C.F.L.; Petruci, J.F.D.S.; Batista, A.D. Novel approaches for colorimetric measurements in analytical chemistry-A review. Anal. Chim. Acta 2020, 1135, 187-203. [CrossRef] [PubMed]

27. Sferopoulos, R. Review of Chemical Warfare Agent (CWA) Detector Technologies and Commercial-Off-The-Shelf Items; Human Protection and Performance Division DSTO Defence Science and Technology Organisation: Victoria, Australia, 2009.

28. Jiang, Y.; Sun, D.-W.; Pu, H.; Wei, Q. Surface enhanced Raman spectroscopy (SERS): A novel reliable technique for rapid detection of common harmful chemical residues. Trends Food Sci. Technol. 2018, 75, 10-22. [CrossRef]

29. CORDIS. European Sensor System for CBRN Applications. Available online: https://cordis.europa.eu/project/id/787031/pl (accessed on 18 June 2021).

30. International Forum to Advance First Responder Innovation. Capability Gaps. Available online: https://www.internationalres ponderforum.org/capability-gaps-overview (accessed on 18 July 2021).

31. EU-SENSE. EU-SENSE About. Available online: https: / /eu-sense.eu/about/ (accessed on 18 July 2021).

32. Dobrowolska-Opala, M.; Gudzbeler, G. European Sensor System for CBRN Applications. In Proceedings of the 9th International Defence and Homeland Security Simulation Workshop, Lisbon, Portugal, 18-20 September 2019; pp. 16-22.

33. Bland, S.A. Chemical, Biological, Radiological and Nuclear (CBRN) Casualty Management Principles. In Conflict and Catastrophe Medicine; Springer: Berlin/Heidelberg, Germany, 2014; pp. 747-770. [CrossRef]

34. NATO Standarisation Agency. ATP-45(D) Warning and Reporting and Hazard Prediction of Chemical, Biological, Radiological and Nuclear Incidents (Operators Manual); NSA: Brussels, Belgium, 2020.

35. CORDIS. Periodic Reporting for period 1-EU-SENSE (European Sensor System for CBRN Applications). Available online: https:/ / cordis.europa.eu/project/id/787031/reporting (accessed on 8 April 2021).

36. Szklarski, L.; Maik, P.; Walczyk, W.M.; Guicheteau, J.A.; Howle, C.R. Developing a novel network of CBRNe sensors in response to existing capability gaps in current technologies. In Proceedings of the Chemical, Biological, Radiological, Nuclear, and Explosives (CBRNE) Sensing XXI, Online, 24 April 2020. [CrossRef]

37. EU-SENSE. Dispersion modelling in EU-SENSE. Available online: https://eu-sense.eu/dispersion-modelling-in-eu-sense/ (accessed on 18 July 2021).

38. EU-SENSE. The final demonstration of the EU-SENSE system. Available online: https:/ / eu-sense.eu/the-final-demonstration-ofthe-eu-sense-system/ (accessed on 22 October 2021).

39. Pich, R.; Maciejewski, P.; Wrzesiński, J.A. Casualties Traffic Organization During Mass Decontamination. Bepieczeństwo i Tech. Pożarnicza 2011, 23, 115-122.

40. Maciejewski, P.; Pich, R.; Wrzesiński, J. Specjalistyczne grupy ratownictwa chemiczno-ekologicznego Państwowej Straży Pożarnejzadania i wyposażenie-część I. Zesz. Nauk./Wyższa Szkoła Oficer. Wojsk Lądowych Im. Gen. T. Kościuszki 2010, 1, 150-160.

41. Maciejewski, P.; Pich, R.; Wrzesiński, J. Specjalistyczne grupy ratownictwa chemiczno-ekologicznego Państwowej Straży Pożarnejzadania i wyposażenie-część II. Zesz. Nauk./Wyższa Szkoła Oficer. Wojsk Lądowych Im. Gen. T. Kościuszki 2010, 2, $217-241$.

42. Maciejewski, P. Ocena Sytuacji Skażeń po Zdarzeniach CBRN z Wykorzystaniem Narzędzi Informatycznych PROMIEN 3.0 Oraz PGO 2014/; National Defence University: Warsaw, Poland, 2016.

43. Maciejewski, P.; Robak, W.; Młynarczyk, M. Protection from CBRN contamination in the Polish Armed Forces. Saf. Fire Technology 2015, 37, 107-118. [CrossRef]

44. NATO Standarisation Agency. ATP-3.8.1—CBRN Defence on Operations; NSA: Brussels, Belgium, 2010; Volume I.

45. Madigan, M.L. HAZMAT Guide for First Responders; CRC Press: Boca Raton, FL, USA, 2017.

46. Jensen, F.V.; Nielsen, T.D. Bayesian Networks and Decision Graphs; Springer: Berlin/Heidelberg, Germany; New York, NY, USA, 2007.

47. Robins, P.; Thomas, P. Non-linear Bayesian CBRN source term estimation. In Proceedings of the 7th International Conference on Information Fusion, Philadelphia, PA, USA, 25-28 July 2005.

48. Mitchell, H.B. Multi-Sensor Data Fusion. An Introduction; Springer: Berlin/Heidelberg, Germany, 2007. [CrossRef]

49. Zainal, Z. Case study as a research method. J. Kemanus. 2007, 9, 1-6.

50. Jung, S.; Woo, J.; Kang, C. Analysis of severe industrial accidents caused by hazardous chemicals in South Korea from January 2008 to June 2018. Saf. Sci. 2020, 124, 104580. [CrossRef]

51. Chen, C.; Reniers, G. Chemical industry in China: The current status, safety problems, and pathways for future sustainable development. Saf. Sci. 2020, 128, 104741. [CrossRef] 
52. Cibulova, K.; Formanek, M.; Priesner, M. The Possible Means Suggested for Improvement of Evaluation of Low Endurable Terrain. In Durability of Critical Infrastructure, Monitoring and Testing, Proceedings of the ICDCF 2016, Šatov, Czech Republic, 6-9 December 2016; Springer: Singapore, 2017; pp. 17-26. [CrossRef]

53. Osei-Kyei, R.; Tam, V.; Ma, M.; Mashiri, F. Critical review of the threats affecting the building of critical infrastructure resilience. Int. J. Disaster Risk Reduct. 2021, 60, 102316. [CrossRef]

54. Hamamoto, S.; Ito, L.; Yoneyama, N.; Tokai, A. Case Study for the Predictive Environmental Risk Assessment of Hexamethylenetetramine Release to the Yodo River during a Massive Tsunami Attack. Water 2021, 13, 549. [CrossRef]

55. Casillas, R.P.; Tewari-Singh, N.; Gray, J.P. Special issue: Emerging chemical terrorism threats. Toxicol. Mech. Methods 2021, 31, 239-241. [CrossRef] [PubMed]

56. Zhu, R.; Hu, X.; Bai, Y.; Li, X. Risk analysis of terrorist attacks on LNG storage tanks at ports. Saf. Sci. 2021, 137, 105192. [CrossRef]

57. Weichbroth, P. Usability attributes revisited: A time-framed knowledge map. In Proceedings of the 2018 Federated Conference on Computer Science and Information Systems, Poznan, Poland, 9-12 September 2018; pp. 1005-1008.

58. Owoc, M.L.; Sawicka, A.; Weichbroth, P. Artificial Intelligence Technologies in Education: Benefits, Challenges and Strategies of Implementation. In Artificial Intelligence for Knowledge Management; Springer: Cham, Switzerland, 2021; pp. 37-58. [CrossRef]

59. Młynarczyk, M.; Maciejewski, P.; Szerszeń, M. CBRN Analysis and SI Promień-Comparison of the Functionality of the Software for the Assessment of Contamination. Saf. Fire Technol. 2015, 40, 133-138. [CrossRef]

60. Huang, X.; Arvin, F.; West, C.; Watson, S.; Lennox, B. Exploration in Extreme Environments with Swarm Robotic System. In Proceedings of the 2019 IEEE International Conference on Mechatronics (ICM), Ilmenau, Germany, 18-20 March 2019; pp. 193-198.

61. Wang, L.L.; Zhou, W.P. On Emergency Response of Swarm Robotics for Chemical Hazards. Adv. Mater. Res. 2014, 1037, 327-333. [CrossRef]

62. Hunt, E.R.; Cullen, C.B.; Hauert, S. Value at Risk strategies for robot swarms in hazardous environments. In Proceedings of the Unmanned Systems Technology XXIII, SPIE Defense + Commercial Sensing, Online, 12 April 2021; Society of Photo-Optical Instrumentation Engineers (SPIE): Bellingham, WA, USA, 2021.

63. Kumar, H.; Kumari, N.; Sharma, R. Nanocomposites (conducting polymer and nanoparticles) based electrochemical biosensor for the detection of environment pollutant: Its issues and challenges. Environ. Impact Assess. Rev. 2020, 85, 106438. [CrossRef]

64. Amgarou, K.; Aspe, F.; Idoeta, R.; Herranz, M. Recommendations for the selection of in situ measurement techniques for radiological characterization in nuclear/radiological installations under decommissioning and dismantling processes. Prog. Nucl. Energy 2021, 137, 103761. [CrossRef] 